Radley and Trinity College, Oxford. During 1906-191 1 he was in India in the Imperial Record Department and the Home Department, acting occasionally as examiner in history for the University of Calcutta. $\mathrm{He}$ resigned in 1911 and for three years occupied himself with literary work. He volunteered for active service in 1914 but was rejected on account of short sight. In 1915 he was appointed to Military Intelligence, War Office. At the beginning of 1919 he was appointed assistant secretary, and in November 1920 secretary, of the Surplus Government Property Disposals Board. He resigned at the end of October 1923 as the work of the Board was then practically completed. In 1924 he became financial officer and secretary to the Senate of the University of London, which post he held until, in 1929, he was appointed the first clerk of the Court. During September I939January 1940 he was private secretary to the Minister of Information (Lord Macmillan). He then resumed his duties as clerk of the Court, acting as deputy to the Principal of the University from June 1940 until he became Acting Principal in October 1941. He was awarded the O.B.E. in 1918 and the C.B.E. in 1923. $\mathrm{He}$ is also an Officier d'Académie Française.

\section{Economics of Reconstruction in Britain}

The Oxford Pamphlet on Home Affairs, "Will the War Make Us Poorer ?" by M. Young and Sir Henry Bunbury (Oxford University Press. No. H.5.; 6d. net), covers some of the ground of the Planning broadsheet "Financial Mysticism" and is a valuable contribution to the lucid thinking required in the appraisal of the Beveridge and other proposals for post-war reconstruction. The authors point out that the only real limits on production are set by the available skill, equipment and organization, and that money for the individual and money for the nation as a whole have very different functions to perform. They also give a warning against the restrictionism that involved us in disasters in 1919 and 1922 , as well as against the danger of spending too fast after victory is won. Mr. Young and Sir Henry Bunbury then discuss three typical questions which the ordinary man is asking himself : Where does all the money come from ? Do private savings do any good? Shall we be poorer after the War? The clear answers given to these questions lead to the conclusion that a few hard and difficult years may, provided we have vision and courage and seize our opportunities, lead us to a better and more securely based society than for many decades. Good organization will be essential, including good monetary organization, with money not as a controller but as a servant of human affairs. The authors insist that we cannot again afford to waste our resources of men and material; we cannot afford unemployment, or to lose great slices of our potential national income by wasting our resources. They are equally emphatic that the expenditure required to rebuild Britain, to implement the Beveridge Plan, and to raise the standard and quality of living for the people of Britain, can be provided if our great human resources are properly utilized and co-ordinated with the resources of other nations.

Water Requirements of Rabbits and Guinea Pigs

THE prevalent idea that rabbits and guinea pigs do not drink still persists widely in spite of all that has been written, said and broadcast. Prof. E. L. Kennaway directs attention to this false impression in a recent issue of the British Medical Journal (1, 760; 1943 ), where he reports that a $2 \cdot 5$-kilo rabbit on a dry diet will take approximately 160 c.c. of water, or 65 c.c. per kilo, daily, which is approximately twice the intake of an average human adult derived from both food and drink. It appears that rabbits fed mainly on a dry diet suffer from both water and food starvation, which is indicated by poor condition and scanty contents of the gut found post-mortem. If such an animal is provided with water, it takes a long drink and then greedily eats the dry food. It is obvious that water is essential for the normal physiology of the rabbit; the flesh (muscle and fat) of mature rabbits contains approximately 67 per cent moisture (King Wilson and Botham, 1934), being higher in males than females fed on similar diets. In comparative tests in feeding $(a)$ dry mash and greenstuff, (b) dry mash and water and (c) dry mash, greenstuff and water (Christian, 1936) the best growth and development was obtained by $(c)$, whereas (a) without drinking water caused impaction of the cæcum. Deprivation of water results in loss of appetite and a decline of 20 per cent in fur growth (Wirth, 1936).

Whether or not a rabbit will drink depends upon the moisture content of the diet; for example, a mixture of roots or potatoes and hay provides sufficient moisture (Brüggemann, 1937) for maintenance, whereas cereal grains and meadow hay required approximately 130 c.c. additional drinking water. When fed hay only, they drank about 150 c.c. of water but individual rabbits varied graatly (118200 c.c.), requiring more in hot weather. Replacement of dry mash by frash tea leaves in mixed diets resulted in a marked decline in water drinking (King Wilson, 1942). For production requirements the water supply is even more important. Although there is more dry matter in rabbit's than cow's milk, deficiency was seen to cause urine drinking and is one of the causes of cannibalism. Very similar results wers observed with guinea pigs on restricted green-food diets.

\section{Bell Laboratories Rubber Research Laboratory}

According to an article (Bell. Lab. Rec., 21, No. 8 ; April 1943) by F. S. Malm, the Bell Laboratories have for many years been actively engaged in research on the chemical and physical properties of rubber and its compounds, to determine the kind of materials required to withstand severe weathering and the constantly changing conditions of temperature, humidity and light exposure. Most of the work has been directed to improving insulating materials made from plantation rubber, but an increasing part has been directed, during recent years, to synthetics such as Buna $\mathrm{S}$ and neoprene. Extensive studies have been carried out on insulation for submarine cables leading to the development of Para-gutta and pressureequalizing materials for loaded telegraph cables. Insulation has been developed for coaxial cables and more recently dielectric materials for ultra-high frequency and micro-wave cables. Rubber jackets were also devised to protect against corrosion in the trans-continental cable being laid between Omaha and Sacramento.

About a year ago the Rubber Group moved to new laboratories at Murray Hill where complete facilities have been provided for studying rubber and its synthetic substitutes and for improving them. In anticipation of a peak load in this work additional equipment was installed including mixers, vulcanizers and apparatus for physical and chemical tests. All 
of this rubber-working equipment is provided with auxiliary apparatus for controlling and recording temperatures, pressures and power consumption. The laboratory rooms are unique in that any of fifteen different services including electric power, air pressure, vacuum, hot and cold water, hydrogen, oxygen and nitrogen in addition to illuminating gas are available at any bench or can easily be made so. To improve the desirable characteristics of a rubber material and suppress the undesirable ones the rubber research organization endeavours to relete the physical characteristics of elastic materials to their molecular structure. Special apparatus is used in studying what happens to the rubber molecules when they are compounded, vulcanized, and destroyed through use. These studies on the mechanism of vulcenization, viscosity, molecular weight and brittleness of rubber and allied substances are associated with current synthetic rubber problems.

\section{Photography of Stars in Daylight}

MANY years ago it was predicted that stars close to the sun should be visible to an observer using a suitable technique. Only recently, however, has such a technique been developed, primarily for investigating the solar corona without waiting for a total eclipse. News has now reached Great Britain that a Swiss attempt to photograph stars in daylight with the aid of a coronagraph has been successful (M. Waldmeier, Z. Astrophys., 21, $269 ;$ 1942). A photograph obtained at Arcsa, at an altitude of 2,050 m. in the Alps, shows Regulus (mag. 1 34) quite clearly at a distance of $12^{\prime}$ (less than the sun's angular radius) from the edge of the solar disk. The observation is possible only by eliminating so far as possible diffracted and diffused light in the apparatus, and by observing at a great altitude to avoid meteorological scattering. The successful photograph was obtained at midday on August 22, 1941, with a 15-sec. exposure through a red filter. Regulus is the only firstmagnitude star within $1^{\circ}$ of the ecliptic, but there are a number of fainter stars (down to third magnitude) which, it is considered, could be photographed in favourable conditions.

One obvious application of the method is to the measurement of the gravitational deflexion of light. The Einstein effect has been observed at several eclipses since 1919 at considerable expense and with many disappointments, and the results have not been all that could be desired. The coronagraph method, if it can be developed so that precision. measurements are possible (at present the objective is an uncorrected single lens, though the field which must be covered is at least $1^{\circ}$ in diameter), will have many advantages. Accidental errors could be considerably reduced by multiplication of observations, for example, and the photographs would be taken under favourable working conditions at an established observatory instead of in the somewhat hectic circumstances of a total eclipse.

\section{Health of New Zealand}

Is his annual report for 1941-42, Dr. M. H. Watt, the director-general of health of New Zealand, states that during this period cerebrospinal fever has become epidemic on a small scale, as is shown by the fact that in the whole country there were 163 cases with 25 deaths among 1,538,620 Europeans, while there were 47 deaths among about 87,000 Maoris. It was found that the meningococcus was widespread among the employees at a freezing company, which suggested that the effect of the intense cold on the nasal mucous membrane lowered the local resistance so as to allow penetration of the organism. Of recent years there has been a considerable increase in known syphilis throughout New Zealand, the number of cases treated at the clinies being $156,192,285$ and 403 during the last four years. There has also been a sharp rise in notification of males suffering from tuberculosis, similar to that found in all the Allied countries and attributable to the special methods employed in the examination of recruits. As regards vital statistics, the birth-rate in Europeans was 22.81 and the deathrate $9 \cdot 81$, while in Maoris these rates were $44 \cdot 77$ and 20.59 respectively. The infant mortality of the Maoris was 125.06 as compared with the European rate of $29 \cdot 74$.

\section{Sudden Rise in Birth-Rate in the United States}

According to an editorial in the January issue of the Statistical Bulletin, the organ of the Metropolitan Life Insurance Company of New York, fairly complete data for 1942 for five large cities in the United States, namely, New York, Boston, Baltimore, Washington, D.C., and New Orleans, show not only that the general level of births for 1942 is materially higher but also that the profile of the curve is completely changed. Instead of a spring and a summer maximum there was a strong upward movement of births beginning about September and continuing almost unbroken to the end of the year. Moreover the level for the entire year is far above that of the period 1938-1939. The sudden increase in births in September and October 1942 would seem to be connected with the outbreak of war in December of the previous year.

\section{Recent Earthquakes}

The United States Coast and Geodetic Survey, in co-operation with Science Service and the Jesuit Seismological Association, has determined the epicentres of three recent earthquakes. The first occurred on March 7 at $3 \mathrm{~h}$. $01.5 \mathrm{~m}$. U.T. from an epicentre situated $57^{\circ} \mathrm{N}$. lat., $164^{\circ} \mathrm{E}$. long. This is in the Pacific Ocean near the east coast of central Kamchatka Peninsula. The second and third were both on March 9, at 3h. 25m. 32s. and 9h. 48m. 37s. U.r. respectively. The first on March 9 was from latitude $42.2^{\circ} \mathrm{N}$, longitude $80.9^{\circ} \mathrm{W}$., which is in the bed of Lake Erie to the west of Erie (city) and north-northeast of the city of Cleveland, and the second on March 9 from an epicentre at latitude $56^{\circ} \mathrm{S}$., longitude $22^{\circ} \mathrm{W}$., which is in the south Atlantic east of the island of South Georgia. All interpretations and calculations are tentative.

\section{Announcements}

AT the recent annual meeting of the Genetical Society the following officers were elected : President, Dr. C. D. Darlington; Vice-Presidents, Dr. R. N. Salaman, Prof. T. J. Jenkin, Prof. R. A. Fisher; Treasurer, Miss E. R. Saunders; Secretaries, Mr. E. B. Ford, University Museum, Oxford; Mr. W. J. C. Lawrence, John Innes Horticultural Institution, Merton, S.W.19.

Erratum.--In the News and Views "Announcements" in NATure of July 10 , we regret that w $\theta$ announced Dr. R. R. Mimms as being appointed lecturer in physies in the University of Birmingham. This is incorrect; for Dr. R. R. Mimms read Dr. R. R. Nimmo. 